\title{
NAA10 p.(D10G) and NAA10 p.(L11R) Variants Hamper Formation of the NatA N-Terminal Acetyltransferase Complex
}

\author{
Nina McTiernan ${ }^{1}\left(\mathbb{D}\right.$, Christine Darbakk $^{2}$, Rasmus Ree $^{1}\left(\mathbb{D}\right.$ and Thomas Arnesen ${ }^{1,2,3, * \mathbb{C}}$ \\ 1 Department of Biomedicine, University of Bergen, N-5020 Bergen, Norway; Nina.Tiernan@uib.no (N.M.); \\ rasmus.ree@uib.no (R.R.) \\ 2 Department of Biological Sciences, University of Bergen, N-5020 Bergen, Norway; darbakk@hotmail.com \\ 3 Department of Surgery, Haukeland University Hospital, N-5021 Bergen, Norway \\ * Correspondence: thomas.arnesen@uib.no
}

Received: 25 October 2020; Accepted: 23 November 2020; Published: 26 November 2020

\begin{abstract}
The majority of the human proteome is subjected to $\mathrm{N}$-terminal $(\mathrm{Nt})$ acetylation catalysed by N-terminal acetyltransferases (NATs). The NatA complex is composed of two core subunits-the catalytic subunit NAA10 and the ribosomal anchor NAA15. Furthermore, NAA10 may also have catalytic and non-catalytic roles independent of NatA. Several inherited and de novo NAA10 variants have been associated with genetic disease in humans. In this study, we present a functional analysis of two de novo NAA10 variants, c.29A >G p.(D10G) and c.32T>G p.(L11R), previously identified in a male and a female, respectively. Both of these neighbouring amino acids are highly conserved in NAA10. Immunoprecipitation experiments revealed that both variants hamper complex formation with NAA15 and are thus likely to impair NatA-mediated Nt-acetylation in vivo. Despite their common impact on NatA formation, in vitro Nt-acetylation assays showed that the variants had opposing impacts on NAA10 catalytic activity. While NAA10 c.29A >G p.(D10G) exhibits normal intrinsic NatA activity and reduced monomeric NAA10 NAT activity, NAA10 c.32T>G p.(L11R) displays reduced NatA activity and normal NAA10 NAT activity. This study expands the scope of research into the functional consequences of NAA10 variants and underlines the importance of understanding the diverse cellular roles of NAA10 in disease mechanisms.
\end{abstract}

Keywords: N-terminal acetylation; NAA10; NAA15; NatA; acetyltransferase; genetic disease; syndrome; X-chromosome

\section{Introduction}

$\mathrm{N}$-terminal $(\mathrm{Nt})$ acetylation is a pivotal protein modification occurring in a majority of eukaryotic proteins, either co- or post-translationally, which is catalysed by a family of eight $\mathrm{N}$-terminal acetyltransferases (NATs) named NatA to NatH [1-3]. The chemical alteration introduced by Nt-acetylation can influence protein folding, complex formation, stability and degradation, and subcellular localisation [3-11].

NatA consists of the catalytic subunit NAA10 and the large auxiliary subunit NAA15 [12-14]. NAA15 changes the substrate specificity of NAA10 upon binding and anchors the complex to the ribosome [15-18]. HYPK is a stable interactor of the NatA complex and is thought to have an inhibitory role ensuring substrate specificity [19-21]. Among the NATs, NatA has the largest substrate pool and co-translationally Nt-acetylates alanine, serine, threonine, valine, cysteine and glycine after the initiator methionine has been cleaved off $[1,18]$. Monomeric NAA10 may also display NAT activity independent of NatA, with a distinct substrate specificity $[15,18]$. Furthermore, NAA10 has been described as a 
lysine acetyltransferase (KAT), acetylating lysine residues of substrates such as $\beta$-catenin, Hsp70 and SAMHD1 [22-25]. In addition to its catalytic roles, NAA10 may act as a non-catalytic regulator of STAT5a and DNMT1 [26-28].

The X-chromosomal NAA10 gene is essential for normal cell function, and dysregulation of NAA10 has been associated with several human cancers such as lung, breast, prostate and colon cancer $[29,30]$. Inherited or de novo missense variants in NAA10 have also been identified as causative of genetic disease in humans [31]. Although individuals harbouring NAA10 missense variants display phenotypic heterogeneity, the phenotypes observed in most affected individuals are developmental delay (DD), intellectual disability (ID) and cardiac anomalies. The severity of disease can range from lethal, as reported for males carrying NAA10 c.109T >C p.(S37P), to only mild clinical manifestations in both males and females with different variants [32-43]. Functional studies have revealed that some NAA10 variants, such as p.(Y43S), p.(I72T), p.(R83C), p.(R83H), p.(V107F), p.(V111G), p.(R116W), p.(F128L) and p.(F128I), negatively impact the catalytic NAT activity of monomeric NAA10 [35-38,41,42]. In contrast, NAA10 p.(S37P), and recently p.(H16P) and p.(N101K), have been shown to impair NatA complex formation and NatA-mediated Nt-acetylation $[33,39,43]$. Moreover, three pathogenic NAA10 variants, p.(S37P), p.(V107F) and p.(R116W), have been shown to disrupt NAA10 binding to imprinting control regions affecting DNMT1 recruitment and genomic imprinting [28]. Thus, different variants are likely to have pleiotropic effects depending on the functional impairment associated with each specific variant. The mechanisms underlying genetic diseases resulting from pathogenic NAA10 variants remain elusive.

Here, we report the functional consequences of two de novo NAA10 variants, c.29A $>$ G p.(D10G) and c.32T $>$ G p.(L11R). NAA10 c.29A $>$ G p.(D10G) was previously identified in a boy who died within 6 months of age [40]. The individual had DD, brain malformations, cardiac abnormalities, hearing loss and dysmorphic features. NAA10 c.32T>G p.(L11R) was previously described in a young girl with DD, brain malformations and strabismus [40].

\section{Results}

\subsection{Analysis of NAA10 Sequence and NatA Structure}

NAA10 is evolutionarily conserved from yeast to human [1]. A NAA10 multiple sequence alignment shows that the affected amino acids D10 and L11 are highly conserved, suggesting an important role in the function and/or stability of NAA10 (Figure 1a). The neighbouring residues D10 and L11 are located in the NAA10 $\alpha 1$ helix, which is part of the NAA10-NAA15 hydrophobic binding surface (Figure 1b). DynaMut [44] was used to identify potential interactions mediated by D10 and L11 with nearby amino acids. The negatively charged D10 was predicted to interact with the positively charged R4 in NAA10 $\beta 1$ through electrostatic and hydrogen bonding. L11 was predicted to form a hydrophobic pocket together with P8, M14, M28, F32 and Y31. The residue R4 interacting with D10 and the hydrophobic residues interacting with L11 are also conserved in many NAA10 orthologues (Figure 1a), supporting a hypothesis that NAA10 p.(D10G) and p.(L11R) variants may disrupt important interactions necessary for proper NAA10 function and/or stability. D10, L11 and the NAA10 residues they interact with were not predicted to directly interact with any NAA15 residues.

\subsection{Complex Formation and Catalytic Activity}

To explore the impact of NAA10-D10G-V5 and NAA10-L11R-V5 on NatA complex formation and catalytic activity, HeLa cells overexpressing either the variants or wildtype NAA10 (NAA10-WT) were subjected to anti-V5 immunoprecipitation (IP), Western blot analysis and Nt-acetylation assays. A striking observation from the Western blot analyses was that less NAA15 co-immunoprecipitated with both variants as compared to NAA10-WT-V5 (Figure 2a,b; Figure S1). These results suggest that both variants impede NatA complex formation, which ultimately is likely to cause reduced NatA-mediated Nt-acetylation in vivo. 

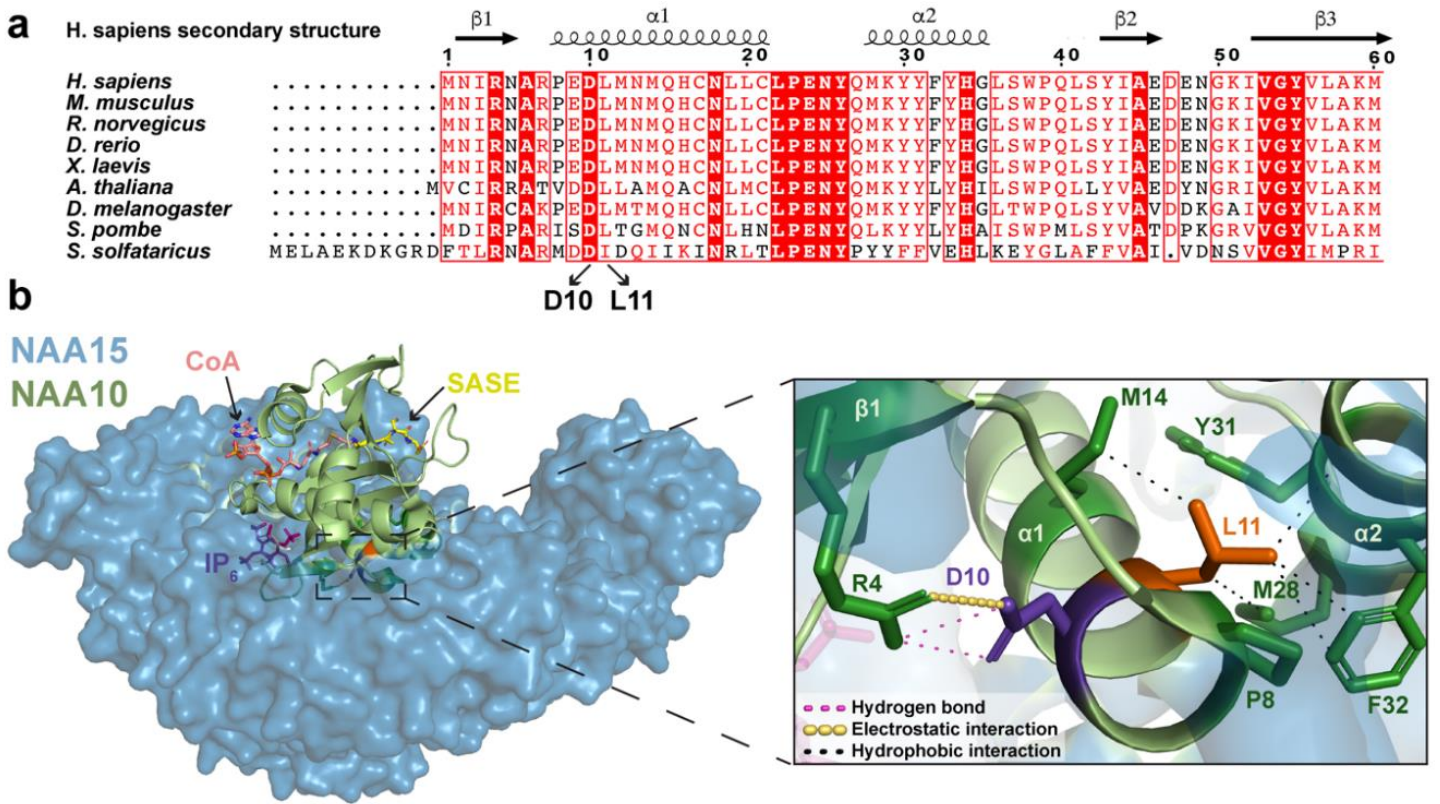

Figure 1. NAA10 multiple sequence alignment and human NatA structure. (a) A multiple sequence alignment of NAA10 sequences from Homo sapiens, Mus musculus, Rattus norvegicus, Danio rerio, Xenopus laevis, Arabidopsis thaliana, Drosophila melanogaster, Schizosaccharomyces pombe and Saccharolobus solfataricus. The amino acids D10 and L11 are highly conserved in the NAA10 sequences (conservation is coloured red). (b) NAA10 (green) and NAA15 (blue) in the human NatA structure (PDB ID: 6C9M) [21] bound with ligand $\mathrm{IP}_{6}$ (magenta). The human NatA structure was superimposed with the substrate (SASE, yellow sticks; CoA, pink sticks) from the S. pombe NatA structure (PDB ID: 4KVM) [15]. A zoomed-in view (right) shows D10 (purple) and L11 (orange) and the interactions they form with surrounding amino acids.

a
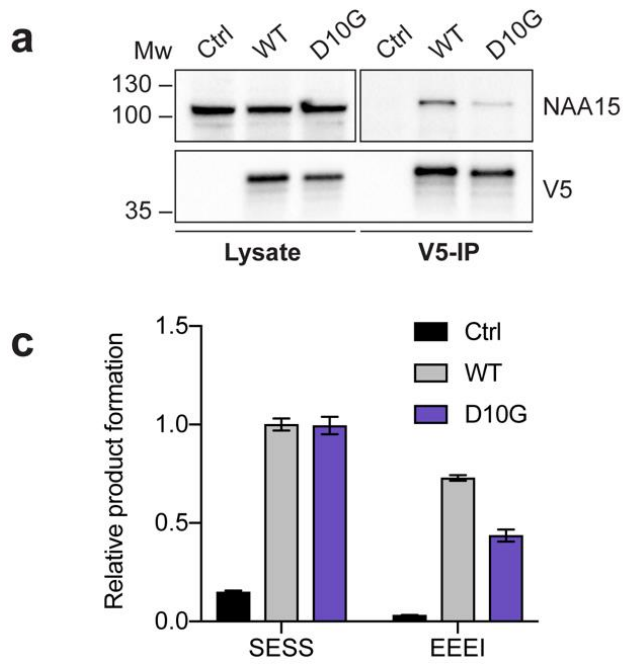

b

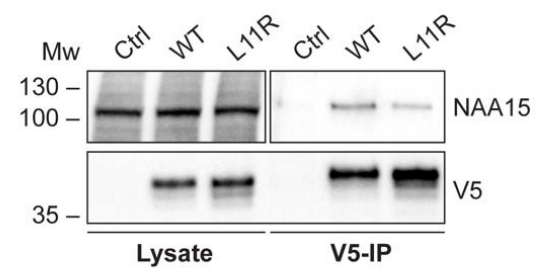

d

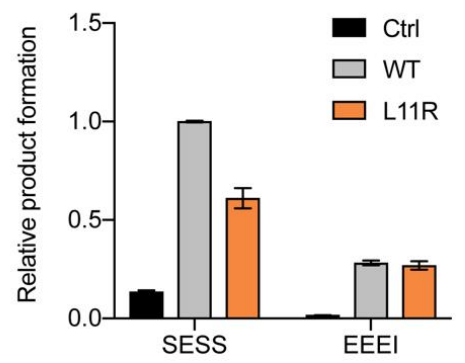

Figure 2. NAA10-V5 immunoprecipitation (IP) and in vitro N-terminal (Nt) acetylation assays. $(\mathbf{a}, \mathbf{b})$ Western blot analyses showing V5-IP of NAA10-WT-V5 and either NAA10-D10G-V5 (a) or NAA10-L11R-V5 (b). The immunoblots were probed with anti-V5 tag and anti-NAA15 antibodies. (c,d) The catalytic activity of the NAA10 variants, NAA10-D10G-V5 (c) and NAA10-L11R-V5 (d), was compared to NAA10-WT-V5 through in vitro Nt-acetylation assays. Negative controls included reactions without peptide and with $\beta$-gal-V5 IP. The measured activities towards the canonical NatA complex substrate $\mathrm{SESS}_{24}$ and the in vitro monomeric NAA10 substrate $\mathrm{EEEI}_{24}$ were normalised to the amount of NAA15 and NAA10-V5 used in the reaction, respectively. The Western blot analyses and $\mathrm{Nt}$-acetylation assays shown are representative of three independent experiments. The Nt-acetylation assays were performed with three technical replicates. 
The catalytic activity of NAA10-D10G-V5 and NAA10-L11R-V5 was investigated through in vitro $\mathrm{Nt}$-acetylation assays (Figure 2c,d). In these assays, $\mathrm{SESS}_{24}$ represented a canonical NatA substrate, while $\mathrm{EEEI}_{24}$ was used as a substrate for monomeric NAA10, which preferentially Nt-acetylates acidic $\mathrm{N}$-termini in vitro. Therefore, the measured catalytic activity against $\mathrm{SESS}_{24}$ and $\mathrm{EEEI}_{24}$ was normalised to the amount of NAA15 and NAA10-V5, respectively. The Nt-acetylation assays revealed that NAA10-D10G-V5 displayed normal NatA catalytic activity, whereas the monomeric NAA10-D10G-V5 NAT activity was reduced by approximately two-fold as compared to NAA10-WT-V5 (Figure 2c). In contrast, NAA10-L11R-V5 demonstrated the opposite effect, the NatA catalytic activity being reduced compared to NAA10-WT-V5, while the monomeric NAT activity was not affected (Figure 2d).

In summary, the experimental evidence suggests that both variants hamper formation of the NatA complex but have different effects on the enzymatic activity of NAA10. NAA10-D10G-V5 showed normal activity in the formed NatA complex but impaired NAA10 monomeric activity, while NAA10-L11R-V5 showed impaired NatA activity but normal monomeric NAA10 activity.

\section{Discussion}

Functional characterisations of different NAA10 variants identified in individuals have revealed that distinct variants can affect the biological roles of NAA10 differently. We report here the functional characterisation of two de novo NAA10 variants, p.(D10G) and p.(L11R). NAA10 p.(D10G) and NAA10 p.(L11R) were previously identified in a boy and a girl, respectively, with phenotypes including developmental delay and brain malformations [40].

Bioinformatic analyses of the NAA10 sequence and structure revealed that D10 and L11, as well as the amino acids they interact with, are highly conserved in NAA10 orthologues (Figure 1a,b), indicating that D10 and L11 are important for NAA10 stability or function. The missense variants NAA10 p.(D10G) and NAA10 p.(L11R) are likely to disrupt the electrostatic interaction between D10 and R4 and the hydrophobic pocket that L11 occupies, respectively. Thus, we hypothesised that these missense variants may cause structural changes that impede the NAA10 active site as well as the interactions between the NAA10 $\alpha 1$ helix and NAA15.

Biochemical experiments were performed to investigate how the variants impacted NatA complex formation and enzymatic activity. Immunoprecipitation of both variants revealed that they had reduced capacity to bind NAA15 compared to NAA10-WT-V5 (Figure 2a,b). This was probably caused by disruption of important interactions between the NAA10 $\alpha 1$ helix and NAA15 [15]. Furthermore, in vitro Nt-acetylation assays showed that NAA10-L11R-V5 had reduced NatA activity and NAA10-D10G-V5 had equal NatA activity compared to NAA10-WT-V5 (Figure 2c,d). Since both variants impair NatA complex formation, it is likely that they both result in less Nt-acetylation of NatA substrates at the ribosome in patient cells. Additionally, NAA10 p.(L11R) probably showed a stronger decrease in Nt-acetylation of NatA substrates than NAA10 p.(D10G) because of its debilitated NatA function, even in the formed NatA complex (Figure 2d).

The monomeric NAA10 NAT activity was only affected by the NAA10 p.(D10G) variant and not NAA10 p.(L11R). This suggests that NAA10 p.(D10G) may affect the NatA-independent roles of NAA10, resulting in diverse downstream effects. To date, no in vivo NAT substrates for monomeric NAA10 have been identified. However, NAA10 has been reported to catalyse the lysine acetylation of several proteins as well as regulating proteins in a non-catalytic manner [3]. Whether these NAT-independent roles of NAA10 are affected by the NAA10 p.(D10G) or NAA10 p.(L11R) variants remains unknown.

The NAA10 p.(D10G) and NAA10 p.(L11R) variants were previously reported by Cheng et al. in an international cohort of individuals with NAA10 variants [40]. In this cohort study, both variants were found to cause a decreased in vitro thermostability of NatA compared to NatA WT, which is in accordance with our IP evidence showing that both variants have a decreased binding affinity for NAA15 in vivo. Furthermore, Cheng et al. tested the in vitro hNatA catalytic activity of NAA10 variants purified from insect Sf9 cells. While both NAA10 p.(D10G) and NAA10 p.(L11R) were found to have reduced NatA activity, NAA10 p.(D10G) was more strongly affected than NAA10 p.(L11R). 
This contradicts our findings in which NAA10 p.(D10G) NatA activity was unaffected in the formed NatA complex. One explanation for this discrepancy could lie in the nature of the experiment; we tested NatA immunoprecipitated from human cells in which potential binding partners and/or post-translational modifications not present in insect cells could influence enzymatic activity. HYPK is a known binding partner of NatA. In fact, Cheng et al. found that the NatA activity of NAA10 p.(L11R) was not reduced when bound to HYPK, which highlights the intricacies of determining the impact of NAA10 variants on the NatA machinery.

Since males only have one $\mathrm{X}$-chromosome, they are generally more severely affected by NAA10 variants than heterozygous females. The boy harbouring NAA10 p.(D10G) died during infancy and had similar clinical features to males harbouring NAA10 p.(S37P) - a lethal condition originally called Ogden syndrome [32]. Similar to NAA10 p.(D10G) and p.(L11R), NAA10 p.(S37P) has been found to impair NatA complex formation and cause reduced Nt-acetylation of some NatA substrates in Ogden-syndrome patient fibroblasts and B-cells. Female carriers of NAA10 p.(S37P) had no severe symptoms, which is possibly explained by their X-chromosome inactivation pattern favouring the WT allele [33]. The impact of X-chromosome inactivation skewing on the clinical manifestations in the female carrying NAA10 p.(L11R) is unclear, as it has not been experimentally tested. Recently, a de novo NAA10 p.(H16P) variant was identified in a young female with severe ID and DD [39]. The NAA10 p.(H16P) variant was located in the NAA10 $\alpha 1$ helix and functional studies revealed that this variant also hampered NatA complex formation. Furthermore, the NAA10 p.(H16P) enzymatic activity resembled that of NAA10 p.(L11R), in that the NatA activity was reduced but the monomeric NAA10 NAT activity was intact. Another NAA10 variant, p.(N101K), was recently described in two unrelated girls with DD and hemihypertrophy [43]. The NAA10 p.(N101K) variant was shown to completely abolish NatA complex formation and NatA enzymatic activity, while its monomeric NAA10 NAT activity was unaffected. NAA10 p.(L11R) may thus have a similar disease mechanism as NAA10 p.(H16P) and NAA10 p.(N101K), in which the phenotypes are caused by impaired NatA Nt-acetylation at the ribosomes.

In conclusion, NAA10 p.(D10G) and NAA10 p.(L11R) appear to be causative of disease through decreased NatA complex formation and consequently reduced NatA-mediated Nt-acetylation of NatA substrates. Since NatA has a large substrate pool, approximately $40 \%$ of the human proteome [3], it is challenging to define all the downstream effects this can cause. NAA10 p.(D10G) may additionally impede the individual roles of NAA10 in the cell. More research is needed in order to unravel the exact disease mechanisms involved with pathogenic NAA10 variants and understand their effect on NAT, KAT and the non-catalytic functions of NAA10.

\section{Materials and Methods}

\subsection{Construction of Vectors}

Vectors containing the NM_003491.3 NAA10 c.29A >G p.(D10G) and NAA10 c.32T>G p.(L11R) variants were generated by mutagenesis of the mammalian expression vector pcDNA3.1/NAA10-V5 using the Q5 Site-Directed Mutagenesis Kit (New England Biolabs, Ipswich, Massachusetts, US) protocol. The primers used for NAA10 c.29A $>$ G p.(D10G) were 5'-AGGCCAGAGGGCCTAATGAAC-3' and $5^{\prime}$-CGCATTGCGGATGTTCATC-3'. The primers used for NAA10 c.32T>G p.(L11R) were $5^{\prime}$-CCAGAGGACCGAATGAACATGC-3' and 5'-CCTCGCATTGCGGATGTT- ${ }^{\prime}$. The variants were verified by sequencing.

\subsection{Bioinformatic Analyses}

A NAA10 multiple sequence alignment was created using the alignment tool Clustal Omega [45] and annotated with sequence conservation and secondary structure information using ESPript 3.0 (http://espript.ibcp.fr) [46]. The NAA10 sequences used were from Homo sapiens (Uniprot ID: P41227), Mus musculus (Uniprot ID: Q9QY36), Rattus norvegicus (Uniprot ID: D3ZUQ2), Danio rerio (Uniprot ID: 
Q7T3B8), Xenopus laevis (Uniprot ID: Q7ZXW3), Arabidopsis thaliana (Uniprot ID: Q9FKI4), Drosophila melanogaster (Uniprot ID: Q9VT75), Schizosaccharomyces pombe (Uniprot ID: Q9UTI3) and Saccharolobus solfataricus (Uniprot ID: Q980R9). PyMOL (version 2.3.1, Schrödinger Inc., New York, NY, US) was used to visualise the human NatA structure (PDB ID: 6C9M) [21] and to superimpose it with the substrate SASE and CoA from S. pombe NatA (PDB ID: 4KVM) [15]. DynaMut [44] was used to predict molecular interactions.

\subsection{Transfection, Immunoprecipitation and Western Blot Analysis}

Five $10 \mathrm{~cm}$ dishes of HeLa cells (ATCC CCL-2) were transiently transfected with either $4 \mu \mathrm{g}$ of WT pcDNA3.1/NAA10-V5 and 2-4 $\mu \mathrm{g}$ of empty pcDNA3.1/V5 vector, $8 \mu \mathrm{g}$ of pcDNA3.1/NAA10-D10G-V5, $6 \mu \mathrm{g}$ of pcDNA3.1/NAA10-L11R-V5 or $6-8 \mu \mathrm{g}$ of pcDNA3.1/LacZ-V5 vector (negative control). Transfection was performed according to the X-tremeGENE 9 DNA Transfection Reagent (Roche, Basel, Switzerland) protocol. After $24 \mathrm{~h}$, the cell medium was replaced and the cells were harvested after $48 \mathrm{~h}$. The harvested cells were lysed in $1 \mathrm{~mL}$ IPH lysis buffer $(50 \mathrm{mM}$ Tris- $\mathrm{HCl} \mathrm{pH}$ 8.0, $150 \mathrm{mM} \mathrm{NaCl}$, $5 \mathrm{mM}$ EDTA, $0.5 \%$ NP-40, $1 \times$ complete EDTA-free protease inhibitor cocktail (Roche)) for $15 \mathrm{~min}$ at $4{ }^{\circ} \mathrm{C}$ on a rotating wheel. Cell debris was removed by centrifugation $\left(17,000 \times g, 4{ }^{\circ} \mathrm{C}, 5 \mathrm{~min}\right)$ and the resulting supernatant was incubated with $4 \mu \mathrm{g}$ of V5-tag mouse monoclonal antibody (Invitrogen, R960-25, Carlsbad, CA, US) at $4{ }^{\circ} \mathrm{C}$ for $2 \mathrm{~h}$ on a rotating wheel. Subsequently, $40 \mu \mathrm{L}$ of pre-washed Dynabeads Protein G (Invitrogen) was added to each sample and incubated overnight. The beads were washed three times in IPH lysis buffer, re-suspended in $90 \mu \mathrm{L}$ acetylation buffer ( $50 \mathrm{mM}$ Tris-HCl pH 8.5, 1 mM EDTA, 10\% Glycerol) and used in the Western blot analyses and Nt-acetylation assays. Immunoblots were probed with V5-tag mouse monoclonal antibody (1:5000 dilution, Invitrogen, R960-25) and NAA15 rabbit polyclonal antibody (1:2000 dilution, BioGenes (Berlin, Germany) [12]). The resulting protein bands were imaged and quantified using ChemiDoc XRS+ System (Bio-Rad, Hercules, CA, US) and Image Lab Software (version 6.0.1, Bio-Rad, Hercules, CA, US).

\subsection{In Vitro N-terminal (Nt)-Acetylation Assays}

In vitro Nt-acetylation assays were performed as described [47]. Triplicate reactions were run in each assay, and contained the following: $10 \mu \mathrm{L}$ immunoprecipitated enzyme, $200 \mu \mathrm{M}$ synthetic oligopeptide SESS $_{24}$ (SESSSKSRWGRPVGRRRRPVRVYP) or EEEI 24 (EEEIAALRWGRPVGRRRRPVRVYP) ( $>95 \%$ purity, BioGenes), $50 \mu \mathrm{M}$ [14C]-Ac-CoA (PerkinElmer, Waltham, MA, US) and acetylation buffer to a final volume of $25 \mu \mathrm{L}$. Negative control reactions contained either immunoprecipitated $\beta$-gal-V5 or no substrate peptide. Reactions were incubated at $37^{\circ} \mathrm{C}$ for $30 \mathrm{~min}$ on a thermoshaker (Eppendorf, Hamburg, Germany). To measure product formation, the reaction was quenched by transferring $23 \mu \mathrm{L}$ of the reaction mixture onto P81 phosphocellulose filter discs (Millipore, Burlington, MA, US). The filter discs were washed three times in $10 \mathrm{mM}$ HEPES buffer ( $\mathrm{pH}$ 7.4) and dried before adding them to $5 \mathrm{~mL}$ Ultima Gold F scintillation mixture (PerkinElmer). Product formation was measured by a TriCarb 2900TR Liquid Scintillation Analyzer (PerkinElmer). The two variants were tested in independent setups compared to the WT enzyme, thus explaining some variability in the relative activity of WT NAA10 towards different substrates.

Supplementary Materials: Supplementary materials can be found at http://www.mdpi.com/1422-0067/21/23/8973/s1.

Author Contributions: Conceptualization, N.M. and T.A.; formal analysis, N.M. and C.D.; writing—original draft preparation, N.M.; writing—review and editing, N.M., C.D., R.R. and T.A.; visualization, N.M.; supervision, N.M., R.R. and T.A.; project administration, T.A.; funding acquisition, T.A. All authors have read and agreed to the published version of the manuscript.

Funding: This research was funded by the Research Council of Norway, Grant number 249843; the Norwegian Health Authorities of Western Norway, Grant numbers 912176 and F-12540-D11382; and the Norwegian Cancer Society, Grant number 171752-PR-2009-0222.

Conflicts of Interest: The funders had no role in the design of the study; in the collection, analysis or interpretation of data; in the writing of the manuscript; or in the decision to publish the results. 


\section{Abbreviations}

$\begin{array}{ll}\text { Nt } & \text { N-terminal } \\ \text { NAT } & \text { N-terminal acetyltransferase } \\ \text { KAT } & \text { lysine acetyltransferase } \\ \text { DD } & \text { developmental delay } \\ \text { ID } & \text { intellectual disability } \\ \text { IP } & \text { immunoprecipitation }\end{array}$

\section{References}

1. Arnesen, T.; Van Damme, P.; Polevoda, B.; Helsens, K.; Evjenth, R.; Colaert, N.; Varhaug, J.E.; Vandekerckhove, J.; Lillehaug, J.R.; Sherman, F.; et al. Proteomics analyses reveal the evolutionary conservation and divergence of N-terminal acetyltransferases from yeast and humans. Proc. Natl. Acad. Sci. USA 2009, 106, 8157-8162. [CrossRef] [PubMed]

2. Bienvenut, W.V.; Sumpton, D.; Martinez, A.; Lilla, S.; Espagne, C.; Meinnel, T.; Giglione, C. Comparative large scale characterization of plant versus mammal proteins reveals similar and idiosyncratic $\mathrm{N}$ - $\alpha$-acetylation features. Mol. Cell. Proteom. 2012, 11, M111.015131. [CrossRef] [PubMed]

3. Aksnes, H.; Ree, R.; Arnesen, T. Co-translational, Post-translational, and Non-catalytic Roles of N-Terminal Acetyltransferases. Mol. Cell 2019, 73, 1097-1114. [CrossRef] [PubMed]

4. Scott, D.C.; Monda, J.K.; Bennett, E.J.; Harper, J.W.; Schulman, B.A. N-terminal acetylation acts as an avidity enhancer within an interconnected multiprotein complex. Science 2011, 334, 674-678. [CrossRef]

5. Behnia, R.; Panic, B.; Whyte, J.R.; Munro, S. Targeting of the Arf-like GTPase Arl3p to the Golgi requires N-terminal acetylation and the membrane protein Sys1p. Nat. Cell Biol. 2004, 6, 405-413. [CrossRef]

6. Setty, S.R.; Strochlic, T.I.; Tong, A.H.; Boone, C.; Burd, C.G. Golgi targeting of ARF-like GTPase Arl3p requires its Nalpha-acetylation and the integral membrane protein Sys1p. Nat. Cell Biol. 2004, 6, 414-419. [CrossRef]

7. Dikiy, I.; Eliezer, D. N-terminal acetylation stabilizes N-terminal helicity in lipid-and micelle-bound alpha-synuclein and increases its affinity for physiological membranes. J. Biol. Chem. 2014, 289, 3652-3665. [CrossRef]

8. Forte, G.M.; Pool, M.R.; Stirling, C.J. N-terminal acetylation inhibits protein targeting to the endoplasmic reticulum. PLoS Biol. 2011, 9, e1001073. [CrossRef]

9. Holmes, W.M.; Mannakee, B.K.; Gutenkunst, R.N.; Serio, T.R. Loss of amino-terminal acetylation suppresses a prion phenotype by modulating global protein folding. Nat. Commun. 2014, 5, 4383. [CrossRef]

10. Shemorry, A.; Hwang, C.S.; Varshavsky, A. Control of protein quality and stoichiometries by N-terminal acetylation and the N-end rule pathway. Mol. Cell 2013, 50, 540-551. [CrossRef]

11. Kats, I.; Khmelinskii, A.; Kschonsak, M.; Huber, F.; Knieß, R.A.; Bartosik, A.; Knop, M. Mapping Degradation Signals and Pathways in a Eukaryotic N-terminome. Mol. Cell 2018, 70, 488-501. [CrossRef] [PubMed]

12. Arnesen, T.; Anderson, D.; Baldersheim, C.; Lanotte, M.; Varhaug, J.E.; Lillehaug, J.R. Identification and characterization of the human ARD1-NATH protein acetyltransferase complex. Biochem. J. 2005, 386, 433-443. [CrossRef]

13. Mullen, J.R.; Kayne, P.S.; Moerschell, R.P.; Tsunasawa, S.; Gribskov, M.; Colavito-Shepanski, M.; Grunstein, M.; Sherman, F.; Sternglanz, R. Identification and characterization of genes and mutants for an N-terminal acetyltransferase from yeast. EMBO J. 1989, 8, 2067-2075. [CrossRef] [PubMed]

14. Park, E.C.; Szostak, J.W. ARD1 and NAT1 proteins form a complex that has N-terminal acetyltransferase activity. EMBO J. 1992, 11, 2087-2093. [CrossRef] [PubMed]

15. Liszczak, G.; Goldberg, J.M.; Foyn, H.; Petersson, E.J.; Arnesen, T.; Marmorstein, R. Molecular basis for N-terminal acetylation by the heterodimeric NatA complex. Nat. Struct. Mol. Biol. 2013, 20, 1098-1105. [CrossRef] [PubMed]

16. Gautschi, M.; Just, S.; Mun, A.; Ross, S.; Rucknagel, P.; Dubaquie, Y.; Ehrenhofer-Murray, A.; Rospert, S. The Yeast $\mathrm{N} \alpha$-Acetyltransferase NatA Is Quantitatively Anchored to the Ribosome and Interacts with Nascent Polypeptides. Mol. Cell Biol. 2003, 23, 7403-7414. [CrossRef]

17. Magin, R.S.; Deng, S.; Zhang, H.; Cooperman, B.; Marmorstein, R. Probing the interaction between NatA and the ribosome for co-translational protein acetylation. PLoS ONE 2017, 12, e0186278. [CrossRef] 
18. Van Damme, P.; Evjenth, R.; Foyn, H.; Demeyer, K.; De Bock, P.-J.; Lillehaug, J.R.; Vandekerckhove, J.; Arnesen, T.; Gevaert, K. Proteome-derived peptide libraries allow detailed analysis of the substrate specificities of $\mathrm{N} \alpha$-acetyltransferases and point to $\mathrm{hNaa10} p$ as the post-translational actin $\mathrm{N} \alpha$-acetyltransferase. Mol. Cell. Proteom. 2011, 10, M110.004580. [CrossRef]

19. Arnesen, T.; Starheim, K.K.; Van Damme, P.; Evjenth, R.; Dinh, H.; Betts, M.J.; Ryningen, A.; Vandekerckhove, J.; Gevaert, K.; Anderson, D. The Chaperone-Like Protein HYPK Acts Together with NatA in Cotranslational N-Terminal Acetylation and Prevention of Huntingtin Aggregation. Mol. Cell. Biol. 2010, 30, 1898-1909. [CrossRef]

20. Weyer, F.A.; Gumiero, A.; Lapouge, K.; Bange, G.; Kopp, J.; Sinning, I. Structural basis of HypK regulating N-terminal acetylation by the NatA complex. Nat. Commun. 2017, 8, 15726. [CrossRef]

21. Gottlieb, L.; Marmorstein, R. Structure of Human NatA and Its Regulation by the Huntingtin Interacting Protein HYPK. Structure 2018, 26, 925-935. [CrossRef]

22. Lim, J.-H.; Park, J.-W.; Chun, Y.-S. Human arrest defective 1 acetylates and activates $\beta$-catenin, promoting lung cancer cell proliferation. Cancer Res. 2006, 66, 10677-10682. [CrossRef] [PubMed]

23. Lim, J.-H.; Chun, Y.-S.; Park, J.-W. Hypoxia-Inducible Factor- $1 \alpha$ Obstructs a Wnt Signaling Pathway by Inhibiting the hARD1-Mediated Activation of $\beta$-Catenin. Cancer Res. 2008, 68, 5177-5184. [CrossRef] [PubMed]

24. Seo, J.H.; Park, J.-H.; Lee, E.J.; Vo, T.T.L.; Choi, H.; Kim, J.Y.; Jang, J.K.; Wee, H.-J.; Lee, H.S.; Jang, S.H.; et al. ARD1-mediated Hsp70 acetylation balances stress-induced protein refolding and degradation. Nat. Commun. 2016, 7, 12882. [CrossRef] [PubMed]

25. Lee, E.J.; Seo, J.H.; Park, J.-H.; Vo, T.T.L.; An, S.; Bae, S.-J.; Le, H.; Lee, H.S.; Wee, H.-J.; Lee, D.; et al. SAMHD1 acetylation enhances its deoxynucleotide triphosphohydrolase activity and promotes cancer cell proliferation. Oncotarget 2017, 8, 68517-68529. [CrossRef] [PubMed]

26. Zeng, Y.; Min, L.; Han, Y.; Meng, L.; Liu, C.; Xie, Y.; Dong, B.; Wang, L.; Jiang, B.; Xu, H.; et al. Inhibition of STAT5a by Naa10p contributes to decreased breast cancer metastasis. Carcinogenesis 2014, 35, 2244-2253. [CrossRef]

27. Lee, C.-F.; Ou, D.S.C.; Lee, S.-B.; Chang, L.-H.; Lin, R.-K.; Li, Y.-S.; Upadhyay, A.K.; Cheng, X.; Wang, Y.-C.; $\mathrm{Hsu}, \mathrm{H}$.-S.; et al. HNa10p contributes to tumorigenesis by facilitating DNMT1-mediated tumor suppressor gene silencing. J. Clin. Investig. 2010, 120, 2920-2930. [CrossRef]

28. Lee, C.-C.; Peng, S.-H.; Shen, L.; Lee, C.-F.; Du, T.-H.; Kang, M.-L.; Xu, G.-L.; Upadhyay, A.K.; Cheng, X.; Yan, Y.-T.; et al. The Role of N- $\alpha$-acetyltransferase 10 Protein in DNA Methylation and Genomic Imprinting. Mol. Cell 2017, 68, 89-103. [CrossRef]

29. Lee, M.-N.; Kweon, H.Y.; Oh, G.T. N- $\alpha$-acetyltransferase 10 (NAA10) in development: The role of NAA10. Exp. Mol. Med. 2018, 50,1-11. [CrossRef]

30. Kalvik, T.V.; Arnesen, T. Protein N-terminal acetyltransferases in cancer. Oncogene 2013, 32, 269-276. [CrossRef]

31. Wu, Y.; Lyon, G.J. NAA10-related syndrome. Exp. Mol. Med. 2018, 50, 85. [CrossRef] [PubMed]

32. Rope, A.F.; Wang, K.; Evjenth, R.; Xing, J.; Johnston, J.J.; Swensen, J.J.; Johnson, W.E.; Moore, B.; Huff, C.D.; Bird, L.M.; et al. Using VAAST to Identify an X-Linked Disorder Resulting in Lethality in Male Infants Due to N-Terminal Acetyltransferase Deficiency. Am. J. Hum. Genet. 2011, 89, 28-43. [CrossRef] [PubMed]

33. Myklebust, L.M.; Van Damme, P.; Støve, S.I.; Dörfel, M.J.; Abboud, A.; Kalvik, T.V.; Grauffel, C.; Jonckheere, V.; $\mathrm{Wu}, \mathrm{Y}$;; Swensen, J.; et al. Biochemical and cellular analysis of Ogden syndrome reveals downstream Nt-acetylation defects. Hum. Mol. Genet. 2015, 24, 1956-1976. [CrossRef] [PubMed]

34. Esmailpour, T.; Riazifar, H.; Liu, L.; Donkervoort, S.; Huang, V.H.; Madaan, S.; Shoucri, B.M.; Busch, A.; $\mathrm{Wu}$, J.; Towbin, A.; et al. A splice donor mutation in results in the dysregulation of the retinoic acid signalling pathway and causes Lenz microphthalmia syndrome. J. Med. Genet. 2014, 51, 185-196. [CrossRef]

35. Saunier, C.; Støve, S.I.; Popp, B.; Gérard, B.; Blenski, M.; Ahmew, N.; Bie, C.; Goldenberg, P.; Isidor, B.; Keren, B.; et al. Expanding the Phenotype Associated with NAA10-Related N-Terminal Acetylation Deficiency. Hum. Mutat. 2016, 37, 755-764. [CrossRef]

36. Casey, J.P.; Støve, S.I.; McGorrian, C.; Galvin, J.; Blenski, M.; Dunne, A.; Ennis, S.; Brett, F.; King, M.D.; Arnesen, T.; et al. NAA10 mutation causing a novel intellectual disability syndrome with Long QT due to N-terminal acetyltransferase impairment. Sci. Rep. 2015, 5, 16022. [CrossRef]

37. McTiernan, N.; Støve, S.I.; Aukrust, I.; Mårli, M.T.; Myklebust, L.M.; Houge, G.; Arnesen, T. NAA10 dysfunction with normal NatA-complex activity in a girl with non-syndromic ID and a de novo NAA10 p.(V111G) variant-A case report. BMC Med. Genet. 2018, 19, 47. [CrossRef] 
38. Støve, S.I.; Blenski, M.; Stray-Pedersen, A.; Wierenga, K.J.; Jhangiani, S.N.; Akdemir, Z.C.; Crawford, D.; McTiernan, N.; Myklebust, L.M.; Purcarin, G.; et al. A novel NAA10 variant with impaired acetyltransferase activity causes developmental delay, intellectual disability, and hypertrophic cardiomyopathy. Eur. J. Hum. Genet. 2018, 26, 1294-1305. [CrossRef]

39. Bader, I.; McTiernan, N.; Darbakk, C.; Boltshauser, E.; Ree, R.; Ebner, S.; Mayr, J.A.; Arnesen, T. Severe syndromic ID and skewed X-inactivation in a girl with NAA10 dysfunction and a novel heterozygous de novo NAA10 p.(His16Pro) variant-A case report. BMC Med. Genet. 2020, 21, 153. [CrossRef]

40. Cheng, H.; Gottlieb, L.; Marchi, E.; Kleyner, R.; Bhardwaj, P.; Rope, A.F.; Rosenheck, S.; Moutton, S.; Philippe, C.; Eyaid, W.; et al. Phenotypic and biochemical analysis of an international cohort of individuals with variants in NAA10 and NAA15. Hum. Mol. Genet. 2019, 28, 2900-2919. [CrossRef]

41. Popp, B.; Støve, S.I.; Endele, S.; Myklebust, L.M.; Hoyer, J.; Sticht, H.; Azzarello-Burri, S.; Rauch, A.; Arnesen, T.; Reis, A. De novo missense mutations in the NAA10 gene cause severe non-syndromic developmental delay in males and females. Eur. J. Hum. Genet. 2015, 23, 602-609. [CrossRef] [PubMed]

42. Ree, R.; Geithus, A.S.; Tørring, P.M.; Sørensen, K.P.; Damkjær, M.; Lynch, S.A.; Arnesen, T. A novel NAA10 p.(R83H) variant with impaired acetyltransferase activity identified in two boys with ID and microcephaly. BMC Med. Genet. 2019, 20, 101. [CrossRef] [PubMed]

43. McTiernan, N.; Gill, H.; Prada, C.E.; Pachajoa, H.; Lores, J.; Arnesen, T. NAA10 p.(N101K) disrupts N-terminal acetyltransferase complex NatA and is associated with developmental delay and hemihypertrophy. Eur. J. Hum. Genet. 2020, 1-9. [CrossRef]

44. Rodrigues, C.H.; Pires, D.E.; Ascher, D.B. DynaMut: Predicting the impact of mutations on protein conformation, flexibility and stability. Nucleic Acids Res. 2018, 46, W350-W355. [CrossRef] [PubMed]

45. Sievers, F.; Wilm, A.; Dineen, D.; Gibson, T.J.; Karplus, K.; Li, W.; Lopez, R.; McWilliam, H.; Remmert, M.; Söding, J.; et al. Fast, scalable generation of high-quality protein multiple sequence alignments using Clustal Omega. Mol. Syst. Biol. 2011, 7, 539. [CrossRef]

46. Robert, X.; Gouet, P. Deciphering key features in protein structures with the new ENDscript server. Nucleic Acids Res. 2014, 42, W320-W324. [CrossRef]

47. Drazic, A.; Arnesen, T. [14C]-Acetyl-Coenzyme A-Based In Vitro N-Terminal Acetylation Assay. In Protein Terminal Profiling: Methods and Protocols; Schilling, O., Ed.; Springer: New York, NY, USA, 2017; pp. 1-8. [CrossRef]

Publisher's Note: MDPI stays neutral with regard to jurisdictional claims in published maps and institutional affiliations.

(C) 2020 by the authors. Licensee MDPI, Basel, Switzerland. This article is an open access article distributed under the terms and conditions of the Creative Commons Attribution (CC BY) license (http://creativecommons.org/licenses/by/4.0/). 